\title{
Three-wheeled scooter taxi: A safety analysis
}

\author{
S MUKHERJEE $^{1}$, D MOHAN $^{1}$, T R GAWADE $^{2}$ \\ ${ }^{1}$ Transportation Research and Injury Prevention Programme, Indian Institute of \\ Technology, Hauz Khas, New Delhi 110016 \\ ${ }^{2}$ TVS Motors Ltd, Hosur, Bangalore 635109 \\ e-mail: sudipto@me.iitd.ernet.in
}

\begin{abstract}
The rollover propensity of a three-wheeled scooter taxi used extensively on SE Asian roads is analysed in this report. A rigid body mathematical model was used to simulate increasing steer, NHTSA J-turn, and Road Edge Recovery maneuvers. The anomaly between public perception of the rollover susceptibility and available crash data has been resolved through finite element (FE) simulation. The optimum configuration of the vehicle and seating arrangement for varying numbers of passengers was determined. The safety of occupants and pedestrians in impact events was analysed through simulation in $\mathrm{MADYMO}^{\mathrm{TM}}$, and cost effective solutions to improve safety were identified.
\end{abstract}

Keywords. Safety analysis; three-wheeled vehicle taxi; stability analysis.

\section{Introduction}

Three-wheel scooter taxis (TSR) form an essential part of public transport for the urban middle class population of India. Apart from India, TSRs are also being used the world over for public transport and for carrying freight. In Dhaka commercially operated three-wheel diesel-powered taxis (the so-called 'baby-taxis') account for more than one-third of the total number of kilometers traveled by all vehicles. In Bangkok 7,400 three-wheelers (the so-called 'tuk-tuks') powered by LPG were on the roads. In Nepal diesel-operated three-wheelers (the so-called 'tempo') have recently been relocated by government out of the Kathmandu valley to encourage the use of battery-operated three-wheelers to curb air pollution (Dhakal 2004). Small, three-wheel vehicles (TWVs) are preferred in place of four-wheeled vehicles because they can negotiate narrow lanes; maneuverability in small turn radii road is better and they are easy to handle on crowded roads. In the case of 4-wheeled vehicles moving with a small turn radius, all wheels do not execute pure rolling motion because of geometric steering constraints. This leads to wheel skid, resistance to the turning action and accentuated tire wear. The wheels of TWVs do not skid during low speed maneuvers. Therefore, maneuverability in small radii turns is more for TWVs as compared to 4-wheelers (figure 1).

These low cost vehicles will remain a major mode of travel in the South Asian region and might move on to Africa as well. Emission-friendly options with $\mathrm{CNG}$ and battery power engines are now available. It has been asserted that it is possible to make a 3-wheel 'car' as stable as a 4-wheel car (Van Valkenburg et al 1982). The poor stability of the three-wheeled 


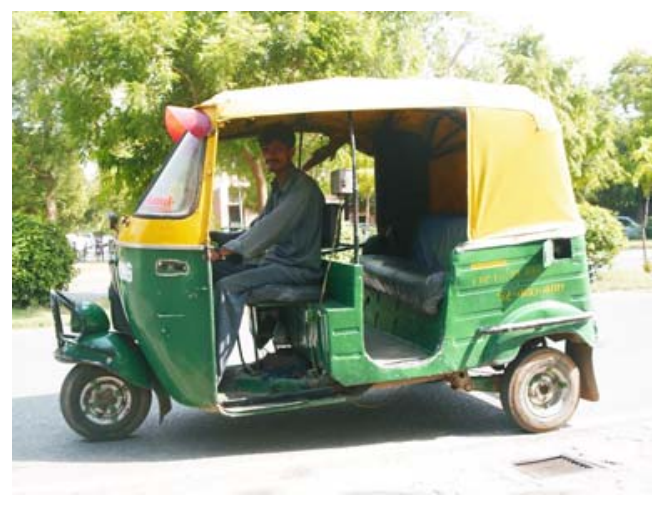

Figure 1. A typical three-wheeled scooter taxi.

ATVs (All Terrain Vehicles), which are used for recreation and fun, is frequently cited as an important factor in accidents (DeLise et al 1988). Relatively higher centre of gravity used to clear obstacles and the lack of differential for the driving rear axle have been cited as contributing factors to rollovers and hence the safety of passengers.

Safety in transportation can be augumented by a chain of social and engineering enhancements like minimizing the number of trips and the distance travelled through city planning, proper design of permanent ways, ability to maneuver out of crash situations, protection for riders in case of crashes and post crash trauma treatment. In this chain, maneuvarability and crash protection are vehicle-specific. Because of their low mass, TWV's will remain at a disadvantage in head on crash situations unless the law mandates crash-compatible heavier vehicles. The high maneuverability of TWV's makes them deft at avoiding vehicular conflicts. This paper addresses the following issues in TWV safety:

(i) What is the rollover propensity of the commonly used TWV using the latest maneuverability assessment tests and how does it compare to conventional vehicles?

(ii) What is the optimum configuration of the TWV to minimize rollover propensity?

(iii) Even if rollover is initiated, under what condition does the TWV roll over?

(iv) What are the measures of injury to occupants and pedestrians in the crash incidents?

\section{Simulations}

In this study, three simulation methodologies have been used, an in-house mathematical model implemented in MATLAB ${ }^{\mathrm{TM}}$, an FE model to study the impact on rollover and a rigid body model implemented in MADYMO ${ }^{\mathrm{TM}}$ to study rider and pedestrian injuries. Recommended procedures like the NHTSA J-turn take approximately 8 seconds and road edge recovery (RER) takes approximately 11 seconds to complete in real time. Carrying out FE simulations for the TWV for this duration would take an estimated 9-10 days on a $2 \mathrm{GHz}$ machine. Hence, it is not practical to run FE solution as a design tool to study rollover because of the large number of iterations involved. A mathematical model of the three-wheeled vehicle with suspension and compliant tires is used to simulate maneuver tests to determine the start of the rollover event, which as specified in the NHTSA tests is the wheel lift-off. Since make and break of contact between road-vehicle-riders is not an issue at this stage, the overheads of the commercial codes can be avoided for computational efficiency. Secondly, the internal variables of the model can be accessed and used to make the simulation consistent with the standard 
tests. It was necessary to include code to model load and traction distribution between tires and simulate driver response as reported by Gawade et al (2005). Large vertical displacement input in the form of road bumps was used to verify the model. An instrumented TSR was run over road bumps and measured vertical acceleration compared with the simulation results for validation.

The state variables at the pre-roll period when there are no impacts have been captured. (The state variables are input as the boundary conditions to FE model to study the impact on rollover and MADYMO ${ }^{\mathrm{TM}}$ models to study injury patterns of occupants and pedestrians.)

\subsection{Parameters of $T W V$}

A TWV rear engine 4 stroke, petrol model manufactured by Bajaj Auto (figure 1) was used for modelling. To estimate mass and inertia properties, a finite element (FE) model of TWV was developed using I-DEAS and assembled in PAM-CRASH ${ }^{\mathrm{TM}}$ from manufacturer drawings. Field measurements of individual parts of a disassembled TWV were used to estimate weight distribution. Center of gravity (CG) location and mass moment of inertia (MI) of empty TSR were also obtained from this FE model.

During experimentation it was necessary for the driver and one passenger to be in the TWV. The average weight of $75 \mathrm{~kg}$ and height $1700 \mathrm{~mm}$ were used. The driver's posture matches the 'Sitting' configuration and the passenger's posture the 'mercury' configuration (NASA 1978). Regression equations for predicting MI about an anatomical axis were used based on anthropometric measurements published by NASA (1978). Based on individual CG and MI for driver, passenger and empty TSR, the composite inertia properties have been calculated using the body-attached fixed frame, Gxyz that is located at the resulting CG. The MI of TSR system represented in Gxyz frame is, $\left[I_{x x}, I_{y y}, I_{z z}\right]=[80 \cdot 64,195 \cdot 66,178 \cdot 54] \mathrm{kg} \mathrm{m}^{2}$. The CG location of the TSR system in the $X_{0} Y_{0} Z_{0}$ frame in a frame, $X_{0} Y_{0} Z_{0}$, whose origin is at the center of track width, vertically below the rear axle on the ground plane (figure 2 ), is given by, $\left[x_{0}, y_{0}, z_{0}\right]=[0 \cdot 61,0,-0 \cdot 62] \mathrm{m}$.

For conducting the maneuver simulation, properties of a 50 percentile Hybrid III dummy were used to standardize the result. Hybrid III dummy (weight $77.11 \mathrm{~kg}$ and height $178 \mathrm{~cm}$ ) inertia properties used were $M I=[69 \cdot 16,180 \cdot 07,171 \cdot 19] \mathrm{kg} \mathrm{m}^{2}, C G=$ $[0 \cdot 67,0,-0 \cdot 57] \mathrm{m}$.

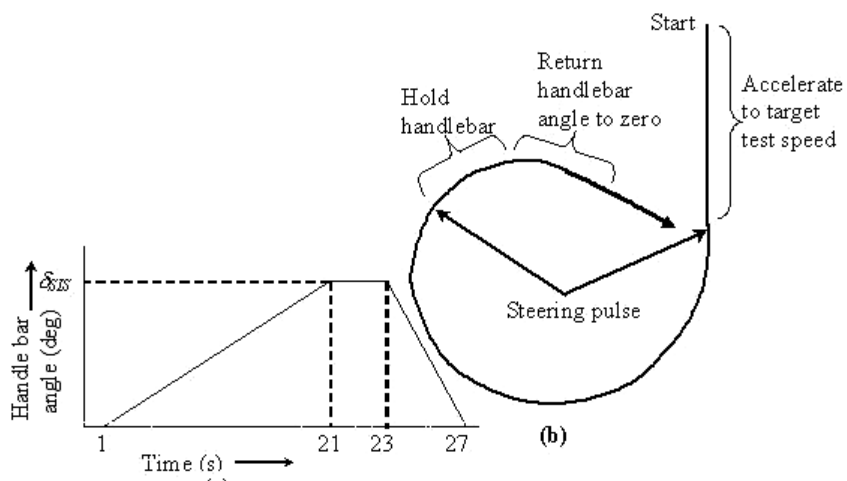

(a)
Figure 2. Schematic of slowly increasing steer (SIS) manoeuver. 
SSF (Static Stability Factor), the ratio of half-track width to the height CG, is close to 1 for the TSR with a driver sitting in it. Coefficients of friction corresponding to peak value as 0.8 and sliding conditions as 0.75 has been used in the simulations. Typical value of rolling resistance coefficient equal to 0.017 for properly inflated tires has been used. This has been extrapolated based on the data available from (Gillespie 1992) for passenger cars, heavy trucks and tractors.

The data available for lateral force of TSR tires has been calculated based on the magic formula (MADYMO 1999) since it allows extension of the tyre behaviour to the whole range of slip angles and vertical loads from the limited quantity of experimental data for small tires reported by Singh et al (1974).

\subsection{Maneuvers}

It has now been accepted that static stability is not a good indicator of vehicle stability during maneuvers and through extensive test programs as reported by NHTSA (Forkenbrock et al 2003, 2002) dynamic tests have been proposed. These take into account the wheel slip angles and the response of the tires; the vehicle's suspension states, and suspension system response in transitional maneuvers and rewards ASC systems, which aid in reducing the chances of rollover.

The slowly increasing steer (SIS) test is used to characterize the vehicle dynamics of each test vehicle by providing a simple and objective way of estimating maximum lateral acceleration. The NHTSA J-turn maneuver entails a sudden and large steering input to model a sudden driver reaction as when avoiding an object on the road. The road edge recovery maneuver models, in an extreme way, what might happen when a driver performs a double lane change or two-wheels off the road recovery maneuver. These tests designed for four wheel vehicles had to be adapted for three-wheeled vehicles.

\subsection{Slowly increasing steer (SIS)}

The SIS maneuver was used to characterize the lateral dynamics of TSR vehicles (figure 2). Straight line motion at the maximum speed of the TSR, $55 \mathrm{~km} / \mathrm{h}(15.3 \mathrm{~m} / \mathrm{s})$ was simulated. In real life, a driver controls the accelerator pedal to maintain the vehicle speed. In the absence of torque input to the wheels, the speed of the vehicle drops off rapidly when on a turn. A controller was designed incorporating the differential torque on two rear wheels to maintain near constant speed during the simulation.

The ideal, no slip path, the TWV would trace is shown in figure $2 \mathrm{~b}$. The radius of curvature traced by the TWV decreases during the steering ramp; remains constant during the handlebar hold and increases while the handlebar angle returns to zero.

We derived the handlebar movement required to obtain a lateral acceleration of $0.8 \mathrm{~g}$ (approximately $8 \mathrm{~m} / \mathrm{s}^{2}$ ) at $22.22 \mathrm{~m} / \mathrm{s}(50 \mathrm{mph}$ as taken in reference (Forkenbrock, et al 2002 , 2003). The radius of turn is estimated to be $61.72 \mathrm{~m}$ and the corresponding steer angle 1.86 degrees is obtained from equation 1 below.

$$
\sin (\text { steer angle })=\text { wheelbase/radius of turn }
$$

At time zero, handle bar position was linearly increased from zero to 1.86 degrees at a rate $0.09 \mathrm{deg} / \mathrm{sec}$. Handle bar position was held constant at 1.86 degrees for two seconds, and then returned to zero in four seconds (figure 2a). The maneuver was performed to the right. The TSR is a symmetrical vehicle and therefore not affected by interchanging left and 


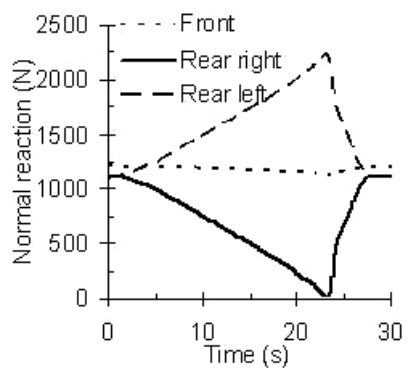

(a)

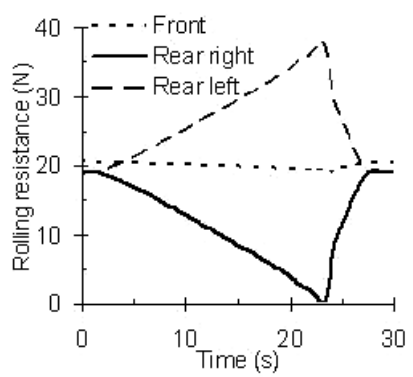

(c)

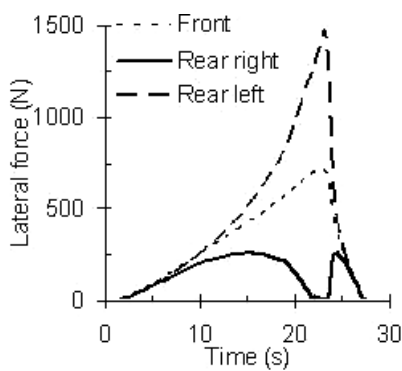

(b)

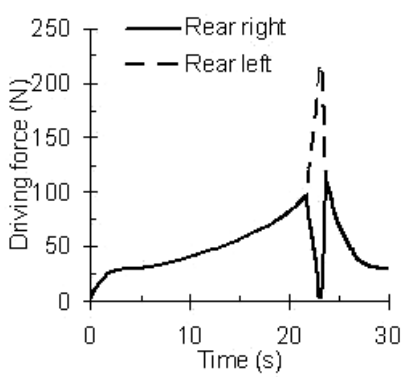

(d)

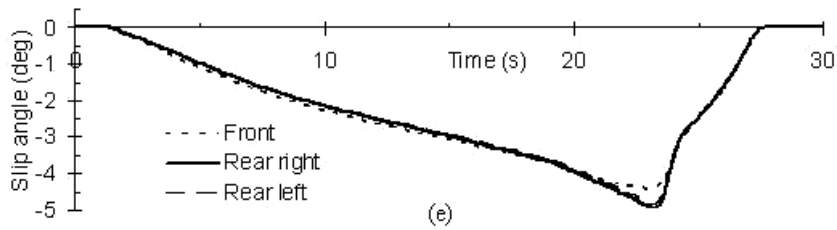

Figure 3. Slowly increasing steer maneuver with a torque controller simulation for a TWV.

right turns. A linear response was found to accurately describe the plot of linear acceleration versus the steer angle from $0.22 \mathrm{~m} / \mathrm{s}^{2}$ to $2.30 \mathrm{~m} / \mathrm{s}^{2}$. This is defined as the linear range of the lateral acceleration response. Using the slope of this approximate straight line, the handle bar position at $1.26 \mathrm{~m} / \mathrm{s}^{2}$ of $0.74 \mathrm{deg}$. was used to calculate NHTSA J-Turn and road edge recovery steering inputs, as described in later sections of this paper.

Variations of forces and slip angles in SIS maneuver with the differential torque controller activated are shown in figures $3 \mathrm{a}-\mathrm{e}$. The variations are for TWV simulated at a forward speed of $13.23 \mathrm{~m} / \mathrm{s}(47.63 \mathrm{~km} / \mathrm{h})$ and maximum handle bar angle $1.82 \mathrm{deg}$. The normal reaction, rolling resistance and the driving force at the rear right wheel approaches to zero at $23.2 \mathrm{~s}$ (figures $3 \mathrm{a}, \mathrm{c}, \mathrm{d}$ ) while the lateral force at the right wheel goes to zero earlier between $21.8 \mathrm{~s}$ to $23 \cdot 3 \mathrm{~s}$ (figure $3 \mathrm{~b}$ ).

Torque required to compensate a deceleration of $1 \mathrm{~m} / \mathrm{s}^{2}$ on a straight line is estimated simply as:

$$
\begin{aligned}
\text { Torque } & =\text { Total mass of TSR } \times \text { wheel radius } \\
& =73.707 \mathrm{~N} . \mathrm{m}
\end{aligned}
$$

The TSR has power input at the rear wheels through a differential. So the torques have been distributed in the inverse proportion of the individual rear wheel velocities. 


$$
\begin{aligned}
\frac{T_{r r}}{T_{r l}} & =\frac{V_{r l S}}{V_{r r S}} \\
T_{r r}+T_{r l} & =73.707 \times\left(V_{c g D}-V_{c g S}\right)
\end{aligned}
$$

where,

$T_{r r}=$ torque input at rear right wheel

$T_{r l}=$ torque input at rear left wheel

$V_{c g D}=$ desired forward velocity of vehicle $\mathrm{CG}$

$V_{c g S}=$ forward velocity of vehicle CG from simulation forward velocity of the rear right wheel from simulation,

$$
V_{r r S}=V_{c g S}-\omega_{z} \sqrt{b^{2}+c^{2}}
$$

Forward velocity of the rear left wheel from simulation,

$$
V_{r l S}=V_{c g S}+\omega_{z} \sqrt{b^{2}+c^{2}}
$$

where, $b$ is longitudinal distance of CG of TSR system from rear axle and $c$ is half-track width.

Using (3) and (4),

$$
\begin{aligned}
& T_{r r}=\frac{73.707 \times\left(V_{c g D}-V_{c g S}\right)}{\left(1+\frac{V_{r r S}}{V_{r l S}}\right)} \\
& T_{r l}=\frac{73.707 \times\left(V_{c g D}-V_{c g S}\right)}{\left(1+\frac{V_{r l s}}{V_{r r S}}\right)}
\end{aligned}
$$

The differential torque control technique was quite effective during SISI maneuver. The entrance speed $15.23 \mathrm{~m} / \mathrm{s}(55 \mathrm{kmph})$ was maintained for a one-second duration and during the maneuver speed drops by $0.69 \mathrm{~m} / \mathrm{s}(4.5$ percent) from the target speed.

\subsection{NHTSA J-turn}

The NHTSA J-Turn was derived from the J-Turn used during NHTSA's Phase II rollover research program (Garrott et al 1999). The handle bar magnitudes were calculated by multiplying the handle bar angle that produced an average of $1.26 \mathrm{~m} / \mathrm{s}^{2}$ in the SIS maneuver by a scalar of 8.0 and it is equal to 5.96 degrees. The rate of handwheel ramp (Forkenbrock et al 2002, 2003) was 1000 degrees per second for the NHTSA J-turn, that is, 74.07 times the handwheel ramp in case of SIS. Maintaining the same factor the initial steering input rate for TSR has been set at 6.88 degrees per second. So the initial steer was performed in 0.87 seconds. The path traced (figure 4) resembles the alphabet 'J', giving the test its name.

To begin the maneuver, the vehicle was simulated in a straight line at a desired entrance speed. The torque control algorithm was deactivated and then the commended handle bar input imposed.

The nominal entrance speeds used in the J-turn maneuver ranged from 5 to $8 \mathrm{~m} / \mathrm{s}$, and were increased in $1 \mathrm{~m} / \mathrm{s}$ increments until a termination condition was achieved. Termination conditions were inner wheel lift in place of $2.0 \mathrm{in}$. lift used in the NHTSA tests. The inner wheel lift is identified by the fact that the reaction exerted by the ground on the wheel reaches zero. When the inner wheel lift was observed, a downward iteration of vehicle speed was used in $0 \cdot 1 \mathrm{~m} / \mathrm{s}$ increments until such a lift was no longer detected. Figure 5 shows the results for the final maneuver. 


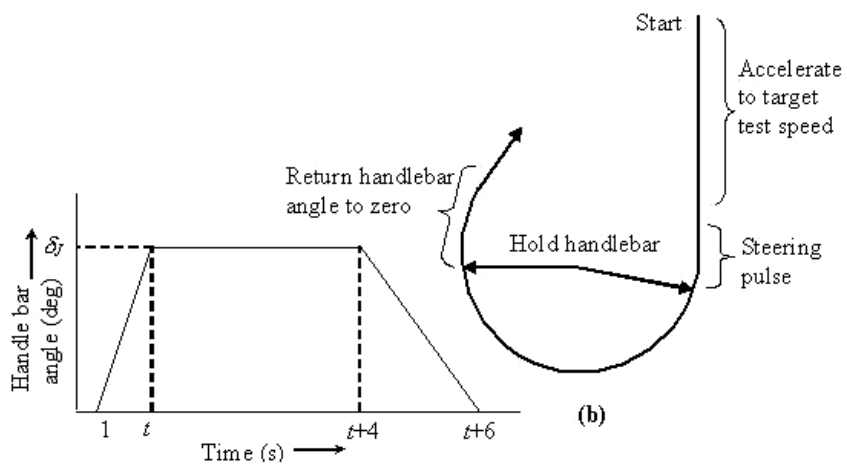

(a)
Figure 4. Schematic of NHTSA J-turn maneuver for vehicles.

\subsection{Road edge recovery (RER)}

The path traced by the TWV is shown in (figure 6). During the first steering pulse, the TWV goes off the road. The second steering (counter steer) mimics the driver's action of coming back onto the road and the third steering indicates the re-entry into the initial path before implementing the steering maneuver.

The initial and countersteer handwheel magnitudes were symmetric, and were calculated by multiplying the handle bar angle that produced an average of $1.26 \mathrm{~m} / \mathrm{s}^{2}$ in the slowly increasing steer maneuver by a scalar of 6.5 and yielding 4.84 degrees. In the rate of handwheel ramp was 720 degrees per second for road edge recovery maneuvers that is 53.33 times the handwheel ramp in the case of slowly increasing steer (Forkenbrock et al 2002, 2003). Maintaining the same factor the steering input rate for TSR has been set to 4.95 degrees per second. So the initial steer was performed in 0.98 seconds. Road edge recovery dwell times were obtained by monitoring the subsequent roll motion of the TSR. In this case an initial steer to the right was input, the steering reversal following completion of the first handle bar ramp occurred when the roll rate of the vehicle first equaled or exceeded -1.5 degrees per second. The handle bar rate of the initial steer and countersteer ramps was 4.95 degrees per second. So the first and third steers were performed in 0.978 seconds and 1.956 seconds.

To begin the maneuver, the vehicle was simulated in a straight line at a desired entrance speed. The torque control algorithm was deactivated and then the commended handle bar input described above imposed.

The nominal entrance speeds used in the J-turn maneuver ranged from 5 to $9 \mathrm{~m} / \mathrm{s}$, and were increased in $1 \mathrm{~m} / \mathrm{s}$ increments when the inner wheel lift was detected. When the inner wheel lift was observed, a downward iteration of vehicle speed in $0.1 \mathrm{~m} / \mathrm{s}$ increments was done until such lift was no longer detected. Figures $7 \mathrm{a}$ and $7 \mathrm{~b}$ show the results for the final maneuver.

\subsection{Maneuver comparisons}

The slowly increasing steer maneuver is the reference maneuver for the NHTSA J-turn and road edge recovery maneuvers. The TSR was simulated at maximum speed (55 kmph) to obtain the linear range of lateral acceleration. Half way between the linear range lateral acceleration $1.26 \mathrm{~m} / \mathrm{s}^{2}$ corresponds to 0.74 degrees of steering angle. NHTSA J-turn and road edge recovery maneuvers were simulated to determine the minimum speed at which wheel lift off occurs. These speeds are $7.98 \mathrm{~m} / \mathrm{s}$ for NHTSA J-turn and $9 \mathrm{~m} / \mathrm{s}$ in case of road edge recovery maneuvers. 


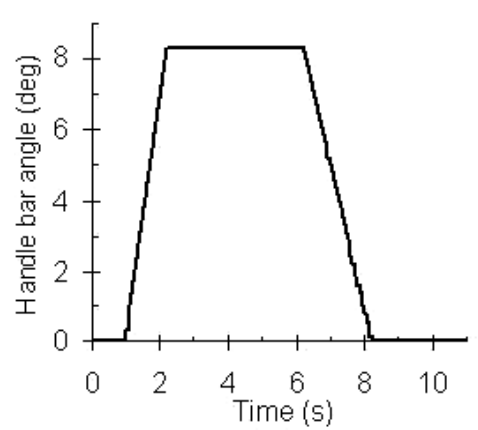

(a)

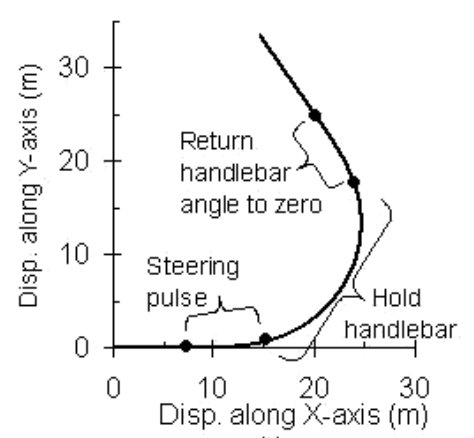

(c)

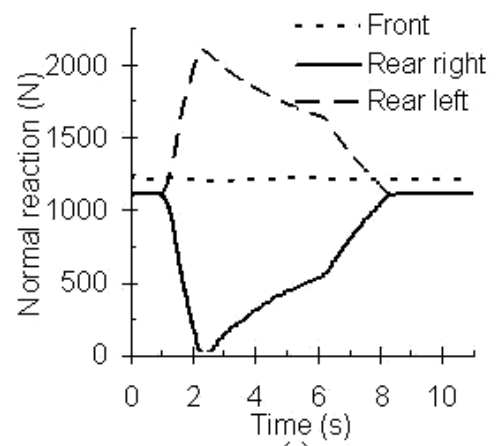

(e)

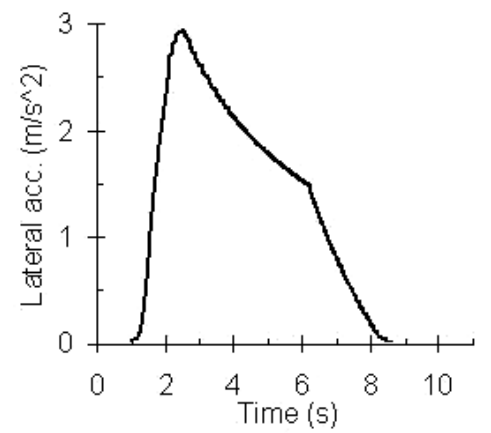

(b)

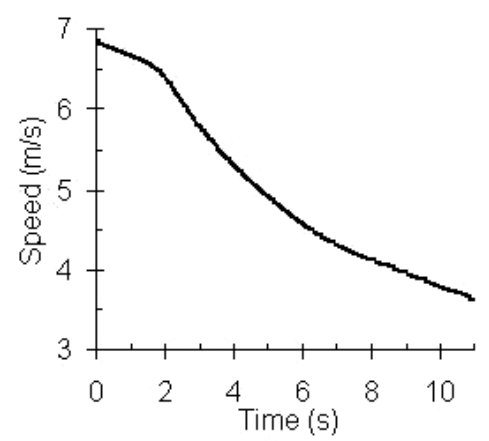

(d)

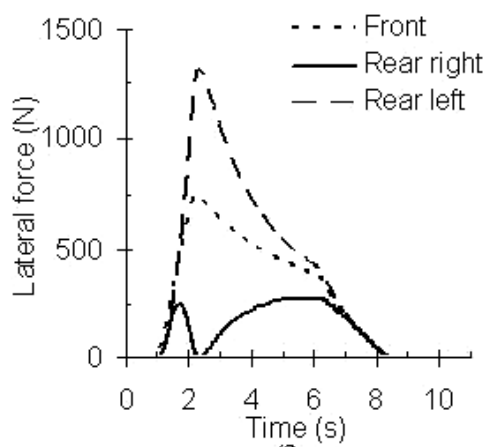

(f)

Figure 5. Variation of various parameters during NHTSA J-turn maneuver for the TWV.

Table 1 shows a comparison of the TWV performance with four SUVs available in Forkenbrock et al $(2002,2003)$.

Clearly the rollover inducing speeds of the TWV is 2 to 3 times lower than that of the best four-wheeled vehicles. However, rollover speed limit of about $30 \mathrm{~km} / \mathrm{h}$ is not very unfavourable when compared to the top speed of about $55 \mathrm{~km} / \mathrm{h}$ for the TWV.

\subsection{Effect of variation in number of occupants}

The study reported above was done with parameters corresponding to the vehicle having the driver and two passengers, the nominal configuration. The studies of two variations of the nom- 

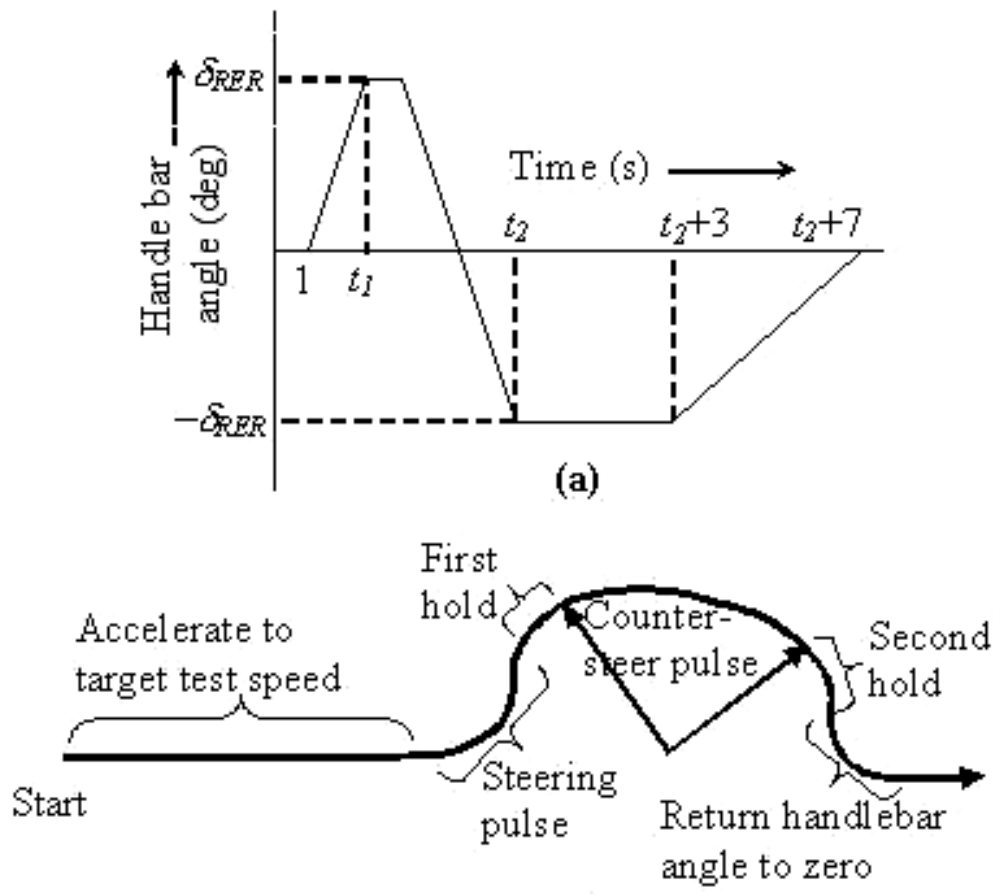

(b)

Figure 6. Schematic of road edge recovery (RER) maneuver for vehicles.

inal model are of interest. There is a need to access the dependence of rollover initiation of the vehicle in relation to the number of passengers. Secondly, for increased number of passengers beyond three, we need to assess if there is a three-wheeled configuration that is more stable.

The basic TWV model with a driver and varying number of passengers on rear seat have been considered. The CG location, mass and moment of inertia change with the inclusion of more passengers. The relevant data as obtained from CAD modelling is shown in table 2 . The four cases that have been considered are: (i) 0-passenger - The nominal TWV model with only one occupant (a driver without passengers). (ii) 1-passenger - driver, and one passenger at the middle of the passenger seat, (iii) 2-passenger - driver, and two passengers located

Table 1. Minimum maneuver entrance speed resulting in one/two wheel lift.

\begin{tabular}{lcc}
\hline Vehicle & NHTSA J-turn (m/s) & RER (m/s) \\
\hline TWV & 7.98 & $9 \cdot 00$ \\
2001 Chevrolet Blazer & 17.29 & 16.09 \\
2001 Toyota 4 Runner (VSC) & & 22.04 \\
2001 Toyota 4 Runner (no VSC) & 20.49 & 16.76 \\
1999 Mercedes ML320 (ESP) & 22.62 & 22.18 \\
1999 Mercedes ML320 (no ESP) & 20.04 & 20.62 \\
\hline
\end{tabular}


Table 2. Parameters of TWV system-effect of number of occupants.

\begin{tabular}{|c|c|c|c|c|c|c|c|c|}
\hline \multirow[b]{2}{*}{ TWV model } & \multirow[b]{2}{*}{$\begin{array}{c}\text { Total No. of } \\
\text { occupants } \\
\left(=\text { driver }+n_{1}\right)\end{array}$} & \multirow[b]{2}{*}{$\begin{array}{c}\text { Total } \\
\text { mass } \\
(\mathrm{kg})\end{array}$} & \multicolumn{3}{|c|}{ CG location (m) } & \multirow{2}{*}{\multicolumn{3}{|c|}{$\begin{array}{l}\text { Moment of inertia } \\
\qquad\left(\mathrm{kg} / \mathrm{m}^{2}\right)\end{array}$}} \\
\hline & & & $\begin{array}{l}\text { From } \\
\text { front } \\
\text { axle }\end{array}$ & $\begin{array}{l}\text { From } \\
\text { rear } \\
\text { axle }\end{array}$ & Height & & & \\
\hline (1) & (2) & $\begin{array}{c}m \\
(3)\end{array}$ & $\begin{array}{c}a \\
(4)\end{array}$ & $\begin{array}{c}b \\
(5)\end{array}$ & $\begin{array}{c}h \\
(6)\end{array}$ & $\begin{array}{l}I_{x x} \\
(7)\end{array}$ & $\begin{array}{l}I_{y y} \\
(8)\end{array}$ & $\begin{array}{l}I_{z z} \\
(9)\end{array}$ \\
\hline 0 -passenger & $1(=1+0)$ & $350 \cdot 5$ & $1 \cdot 303$ & 0.697 & $0 \cdot 602$ & $76 \cdot 2$ & $197 \cdot 3$ & $181 \cdot 7$ \\
\hline 1-passenger & $2(=1+1)$ & $427 \cdot 6$ & $1 \cdot 369$ & 0.631 & $0 \cdot 661$ & $85 \cdot 1$ & $216 \cdot 0$ & $194 \cdot 3$ \\
\hline 2-passenger & $3(=1+2)$ & $504 \cdot 7$ & 1.416 & 0.584 & 0.701 & $114 \cdot 6$ & $241 \cdot 0$ & $216 \cdot 0$ \\
\hline 3-passenger & $4(=1+3)$ & $581 \cdot 8$ & 1.450 & 0.550 & 0.731 & $122 \cdot 8$ & 254.8 & $224 \cdot 3$ \\
\hline
\end{tabular}

$n_{1}$ is number of passengers

symmetrically, on the passenger seat, (iv) 3-passenger - driver, and three passengers on the passenger seat.

Rollover maneuvers for each case have been simulated as per NHTSA rollover procedure and the results are listed in table 3 .
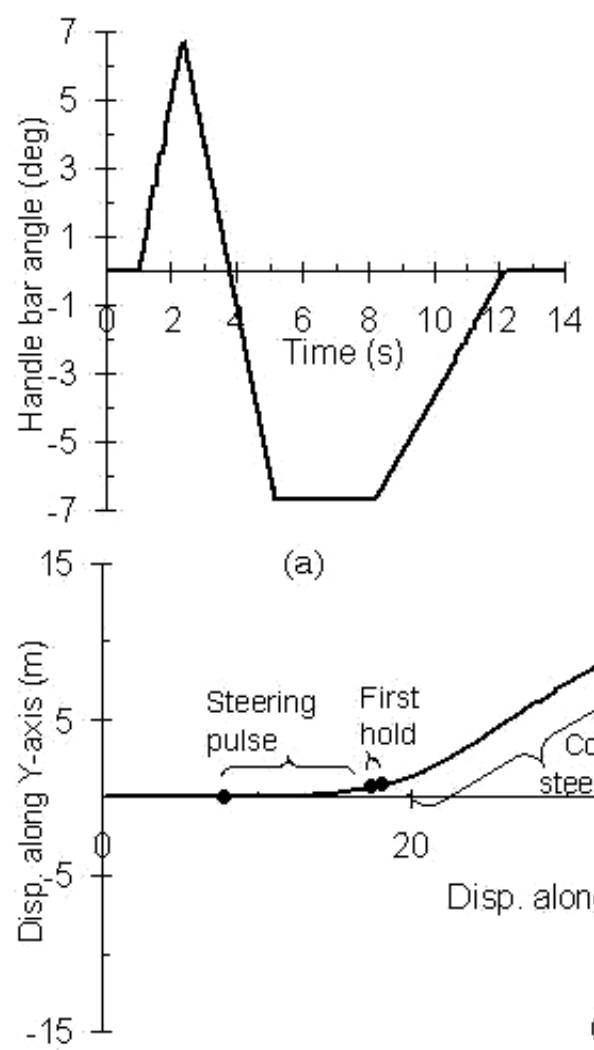

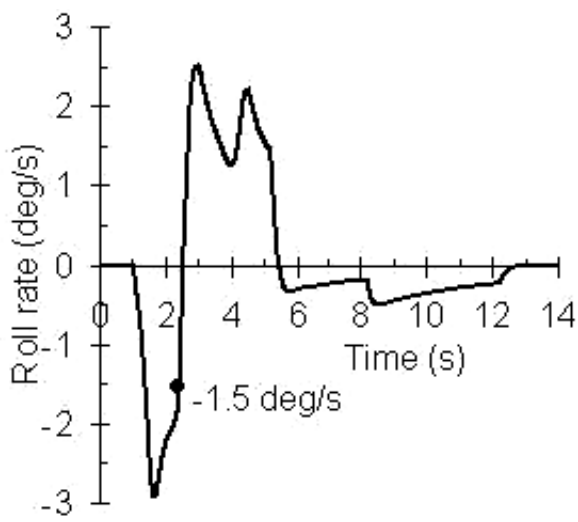

(b)

(c)

Figure 7. (Continued) 


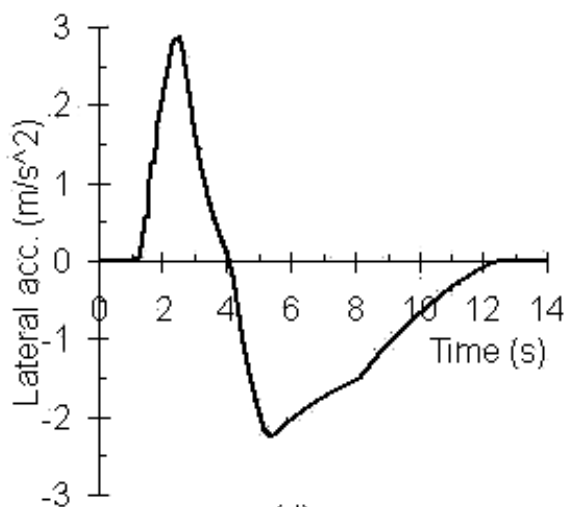

(d)

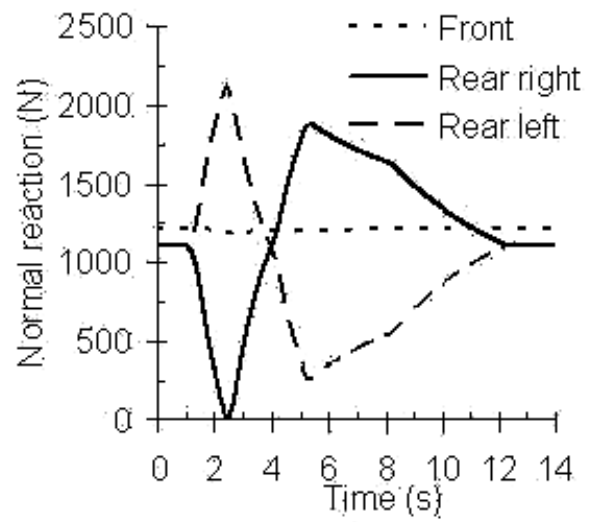

(f)

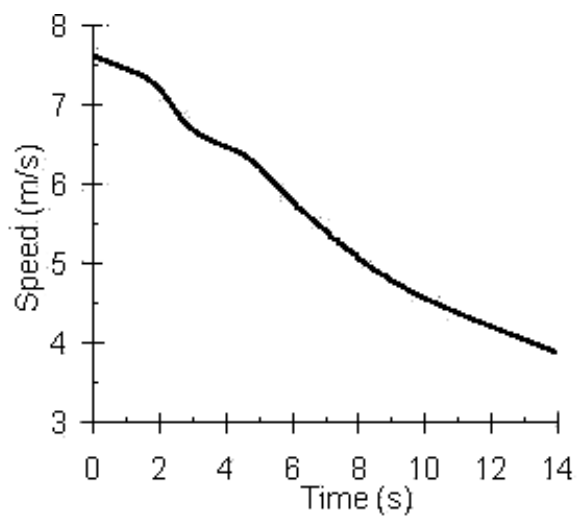

(e)

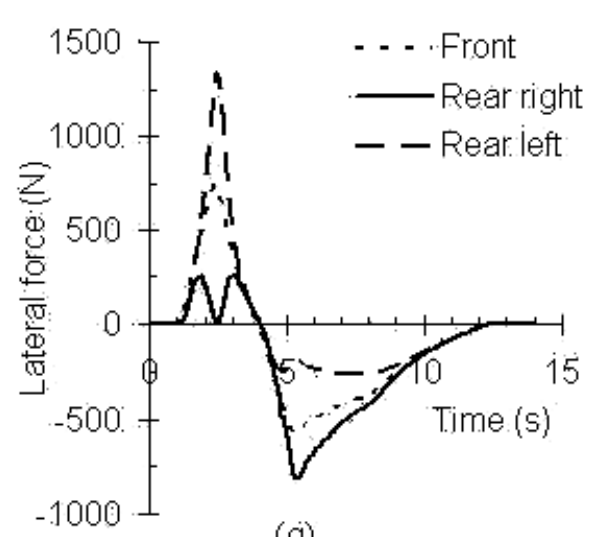

(g)

Figure 7. Time history during road edge recovery maneuver (contd. from previous page figure 7a).

As inclusion of each occupant raises the centre of gravity (CG) height, static stability criterion would indicate that the TWV with minimum number of occupants would be most stable in rollover maneuvers. However, figure 8 is a graphical representation of the key result in table 3, illustrates that the 1-passenger configuration allows the largest speed and is the most stable.

\subsection{Vehicle scale-up studies}

The presentation so far has been on a specific model of the TWV; which needs to be generalized to study models with sizes and seating arrangement in rollover. The difficulty is that a wide range of TWV have not been commercially produced unlike four-wheel vehicles; and even if they have been, the data is not available. The approach adopted was to geometrically scale the models and use the trends in four-wheeled vehicles to fill in the missing data.

The variation of the gross four-wheeled vehicle weight for existing vehicles against length and width has been presented graphically (Bekker 1962). The length of cars and trucks is not a direct function of vehicle width. Cars and trucks, as a class, have the same width which is approximately $1.78 \mathrm{~m}$ (70 in) for cars and 2.5-2.6 m (100 in) for trucks. Vehicle length grows freely until vehicle weight reaches approximately 5 tons. The length of a vehicle is forced by 


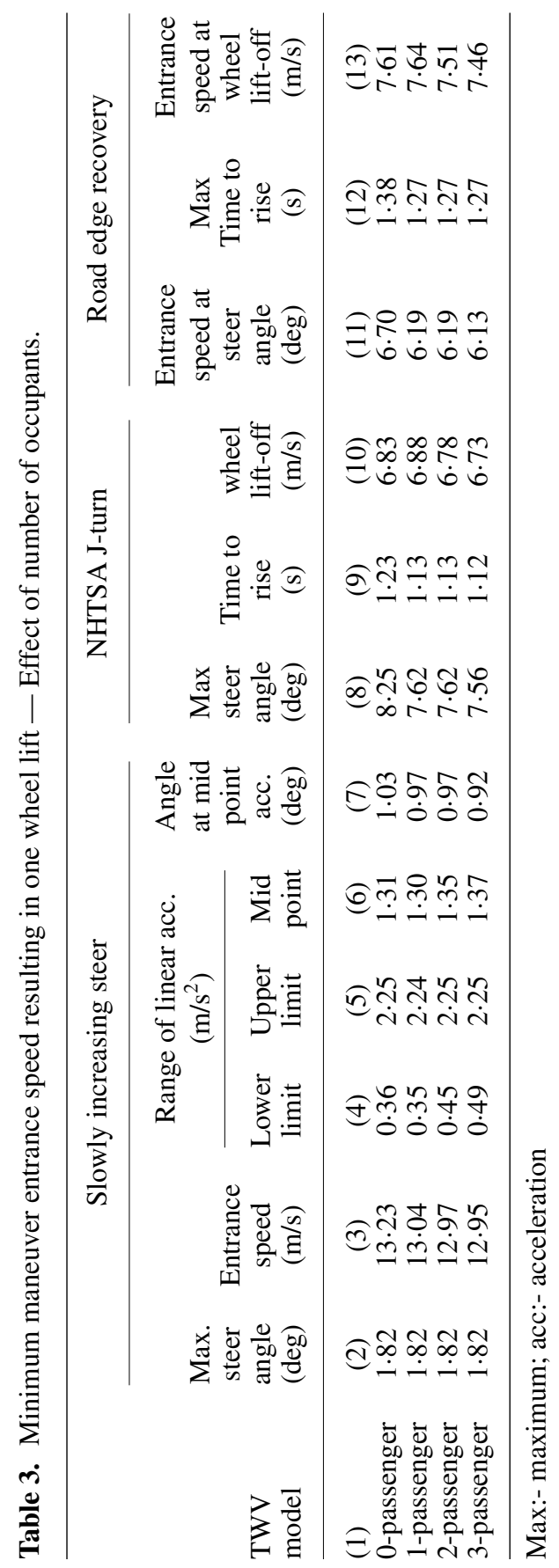




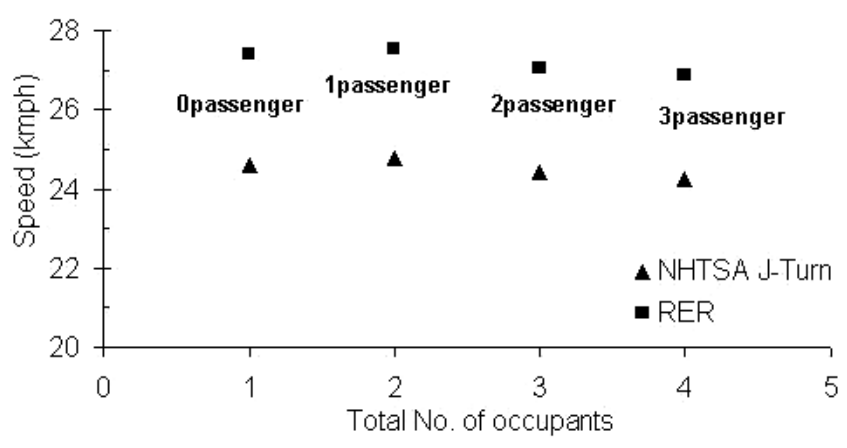

Figure 8. Variation of TWV rollover limits with increase in total number of occupants.

maneuverability requirements on the road and secondly by the radii of curvature of the road. When negotiating a narrow tortuous path, a vehicle with large overall length may stall.

Addition of passengers in the driver's compartment was not considered in the scale-up analysis of TWV because currently these vehicles are chauffeured and the integrity of the driver cabin was maintained. To constrain the overall size of TWV the limits were selected to that of the Maruti-800 car, the smaller, popular, passenger car in India. It was presumed that there would be no commercial viability for larger TWV. The mathematical model of TWV includes track width and wheel base as the input parameters. Four combinations of track width and wheel base have been tried out for scale-up models, with the combination of track width $(1.15 \mathrm{~m}$ or $1.44 \mathrm{~m})$ and wheel base $(2 \mathrm{~m}$ or $2.175 \mathrm{~m})$ as follows.

Track width $1.15 \mathrm{~m}$ and wheel base $2 \mathrm{~m}$ - TaWa1f and TaWa1b,

Track width $1.44 \mathrm{~m}$ and wheel base $2 \mathrm{~m}-\mathrm{T}+\mathrm{Wa1f}$ and $\mathrm{T}+\mathrm{Wa} \mathrm{b}$,

Track width $1.15 \mathrm{~m}$ and wheel base $2.175 \mathrm{~m}-\mathrm{TaW}+2 \mathrm{ff}$, TaW $+2 \mathrm{bf}$ and $\mathrm{TaW}+2 \mathrm{fb}$,

Track width $1.44 \mathrm{~m}$ and wheel base $2.175 \mathrm{~m}-\mathrm{T}+\mathrm{W}+2 \mathrm{ff}, \mathrm{T}+\mathrm{W}+2 \mathrm{bf}$ and

$$
\mathrm{T}+\mathrm{W}+2 \mathrm{fb} \text {. }
$$

Combinations of forward facing seating and reverse facing seating were investigated for these cases, leading to more than one configuration for the same outer dimension.

To determine the maximum number of passengers in the vehicle, the (ISO 1999/IS 1995) standards for occupant comfort was used as a guideline. A width of $1.10 \mathrm{~m}$ accommodates two passengers while a width of $1.44 \mathrm{~m}$ accommodates three sitting 50th percentile passengers. Different passenger seating configurations, as shown in table 4 were evaluated. For visualization, images of 3-D models from PAM-CRASH ${ }^{\mathrm{TM}}$ for showing the seating arrangement of the occupants have been included. These models do not correspond to any vehicles that are currently in production. So, direct measurement of the properties was not possible. Some parameters have been estimated by scaling and CAD modelling while specialized approaches were adopted for the parameters that do not scale geometrically.

Estimation of suspension properties (stiffness, damping, allowable compression/extension), weight of an engine and battery, tire stiffness, cornering stiffness and tire dimensions was not by scaling. An approach based on ergonomic compatibility was adopted. The human body has a known tolerance band in the frequency spectrum independent of the type of vehicle. Hence, it was ensured that the fundamental frequency for the main suspension, the static deflection at individual wheel and the damping factor for each suspension were not changed from the existing TWV model. Tire stiffness was based on the total static deflection at each wheel equal to that in the existing TWV. Based on the CG location of TWV loaded to its full capacity 
Table 4. Range of TWV scale-up models.

\begin{tabular}{|c|c|c|c|c|}
\hline \multirow[b]{2}{*}{$\begin{array}{l}\text { TWV } \\
\text { model }\end{array}$} & \multirow[b]{2}{*}{ 3-D model } & \multirow[b]{2}{*}{ Seating arrangement } & \multicolumn{2}{|c|}{ Specifications (m) } \\
\hline & & & $\begin{array}{l}\text { Track } \\
\text { width }\end{array}$ & $\begin{array}{c}\text { Wheel- } \\
\text { base }\end{array}$ \\
\hline (1) & (2) & (3) & (4) & (5) \\
\hline TaWa1f & & 200 & $1 \cdot 15$ & $2 \cdot 0$ \\
\hline TaWa1b & & $\theta \prec$ & $1 \cdot 15$ & $2 \cdot 0$ \\
\hline T+Wa1f & & 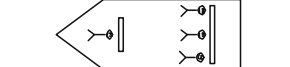 & 1.44 & $2 \cdot 0$ \\
\hline $\mathrm{T}+\mathrm{Wa} 1 \mathrm{~b}$ & & & 1.44 & $2 \cdot 0$ \\
\hline $\mathrm{TaW}+2 \mathrm{ff}$ & & & $1 \cdot 15$ & $2 \cdot 175$ \\
\hline $\mathrm{TaW}+2 \mathrm{bf}$ & & $\left|\begin{array}{lll}0 & <>0 \\
0<<>0\end{array}\right|$ & $1 \cdot 15$ & $2 \cdot 175$ \\
\hline $\mathrm{TaW}+2 \mathrm{fb}$ & & & $1 \cdot 15$ & $2 \cdot 175$ \\
\hline $\mathrm{T}+\mathrm{W}+2 \mathrm{ff}$ & & 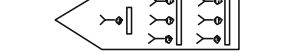 & 1.44 & $2 \cdot 175$ \\
\hline $\mathrm{T}+\mathrm{W}+2 \mathrm{bf}$ & & 0 & 1.44 & $2 \cdot 175$ \\
\hline $\mathrm{T}+\mathrm{W}+2 \mathrm{fb}$ & & 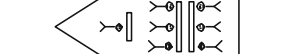 & 1.44 & $2 \cdot 175$ \\
\hline
\end{tabular}




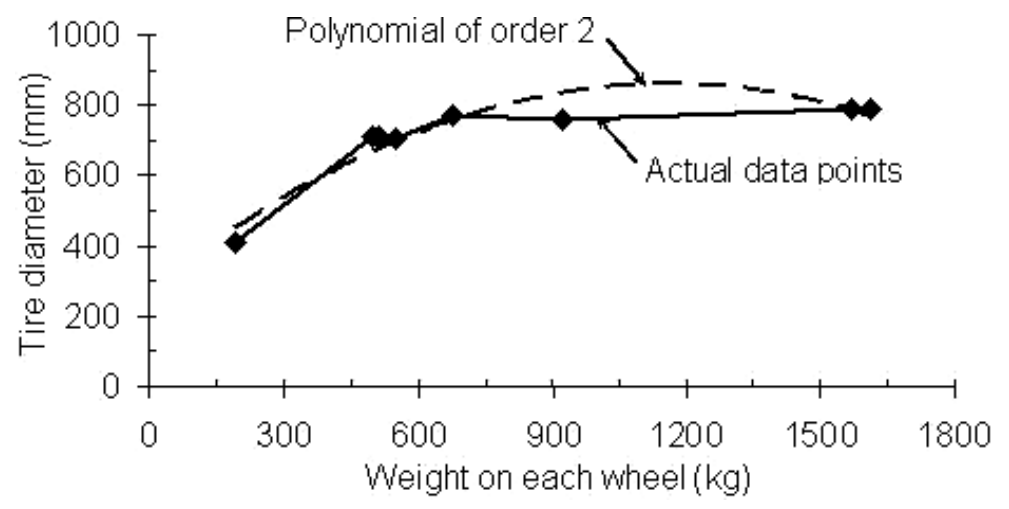

Figure 9. Estimation of tire diameter from data available from manufacturers.

the load distribution on individual wheels was calculated and the parameters for the main suspension and the tire compliance based on the load on each wheel was calculated separately. Engine and battery masses were scaled proportional to gross vehicle weight (GVW). To estimate the tire diameters, the variation of GVW per wheel with tire diameter was established as a polynomial fit from data available from manufacturers' web sites (figure 9). The zone of interest is around $400 \mathrm{~kg}$ and the polynomial fit represents the zone of interest in this particular case. The tire diameters were selected by interpolating this data.

All scale-up models of TWV with $1.5 \mathrm{~m}$ track width show wheel lift-off during the SIS maneuver at a maximum speed $13.89 \mathrm{~m} / \mathrm{s}(50 \mathrm{~km} / \mathrm{h})$. Whereas the scale-up models with track width $1.44 \mathrm{~m}$ do not show wheel lift-off during the SIS maneuver even at a $10 \%$ higher speed than the maximum possible speed. Increasing the track width stops the rollover in the SIS maneuver and should be implemented as a safety measure.

The rear facing configuration of TWV with single row of passengers has more rollover resistance as compared to forward facing configuration. In case of two rows of passenger seats, the forward facing configuration has more rollover resistance as compared to other seating arrangements. The TWV models with first row of passengers facing backward and second row facing forward has the least rollover resistance. Irrespective of the variation in individual parameters discussed above, the TWV with track width $1.44 \mathrm{~m}$, wheelbase $2 \mathrm{~m}$ and one row of backward facing passenger seat is the optimum from a maximum rollover resistance perspective. The entrance speed at the wheel lift-off threshold in the NHTSA J-turn maneuver is $8.14 \mathrm{~m} / \mathrm{s}(29.3 \mathrm{~km} / \mathrm{h})$ and the RER maneuver is $9.22 \mathrm{~m} / \mathrm{s}(33.2 \mathrm{~km} / \mathrm{h})$.

\subsection{Does the TWV really flip over?}

The rollover stability of TWV is generally perceived to be poor based on anecdotal accounts. However, police data from Delhi (Ojha, 2001) and Hyderabad (Dandona \& Mishra 2004), do not show a greater injury rate for TWV. One of the issues addressed here is to understand the anomaly between public perception and statistically reported results of injury probabilities.

Simulations were conducted using the FE package PAMCRASH ${ }^{\mathrm{TM}}$ to study the crash event. The TWVs bottom portion of the front shield acts like an in-built outrigger, forcing the vehicle out of the turn in spite of the steering input, thus restoring the vehicle to an upright position. The simulations indicate that it is improbable that on a flat level road the TWV would flip over due to a maneuver at speeds up to $9.5 \mathrm{~m} / \mathrm{s}(34 \mathrm{~km} / \mathrm{h})$. Runs of the vehicle with simulated 


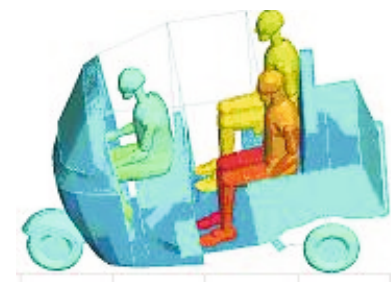

$0 \mathrm{~ms}$

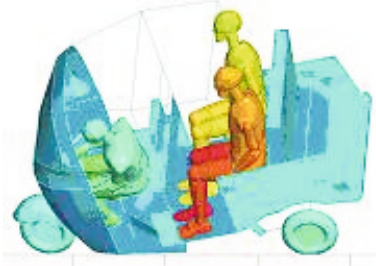

$300 \mathrm{~ms}$

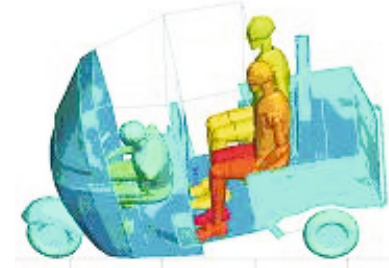

$600 \mathrm{~ms}$

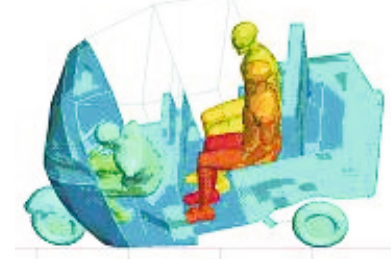

$900 \mathrm{~ms}$

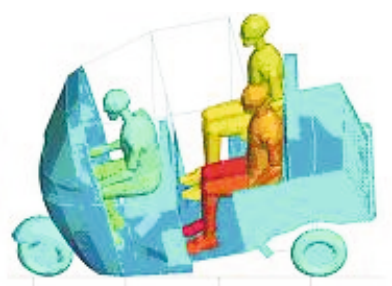

$100 \mathrm{~ms}$

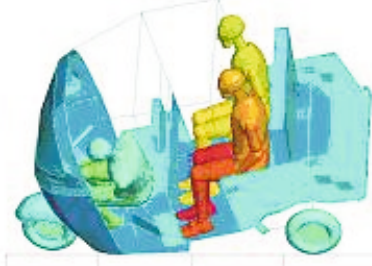

$400 \mathrm{~ms}$

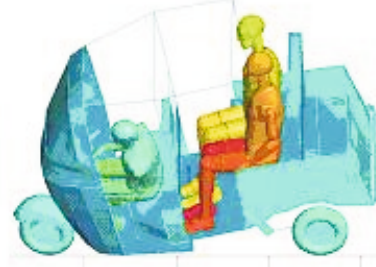

$700 \mathrm{~ms}$

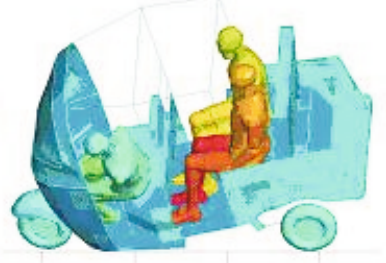

$1000 \mathrm{~ms}$

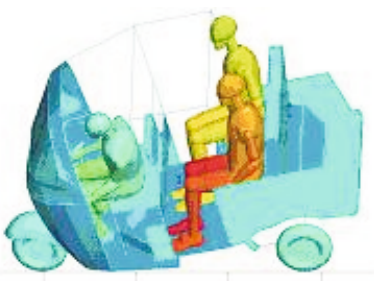

$200 \mathrm{~ms}$

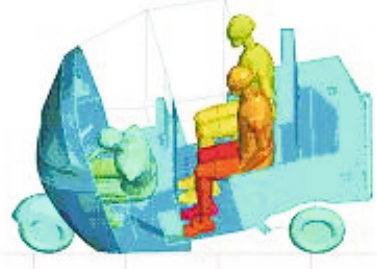

$500 \mathrm{~ms}$

Figure 10. TWV rollover simulation snapshots at $100 \mathrm{~ms}$ intervals.

potholes up to $152 \mathrm{~mm}$ depth and vehicle on the turn also failed to flip over. A significant lateral impact might be required to flip the vehicle over. This leads to the interesting observation that users sense the propensity of the TWV to have wheel lift-off and hence are uncomfortable with it. Since the vehicle does not flip over in spite of a lift-off, the recorded crash statistics does not show any added rollover tendencies (figure 10).

\subsection{Pedestrian and occupant safety issues}

Simulations for pedestrian impact with frontal and side of the vehicle were developed and run with varying offset at vehicle speeds of 10,20 and $30 \mathrm{~km} / \mathrm{h}$ with braking of $0.2 \mathrm{~g}$. The injury severity of different body parts for pedestrian as well as occupant was estimated through these 


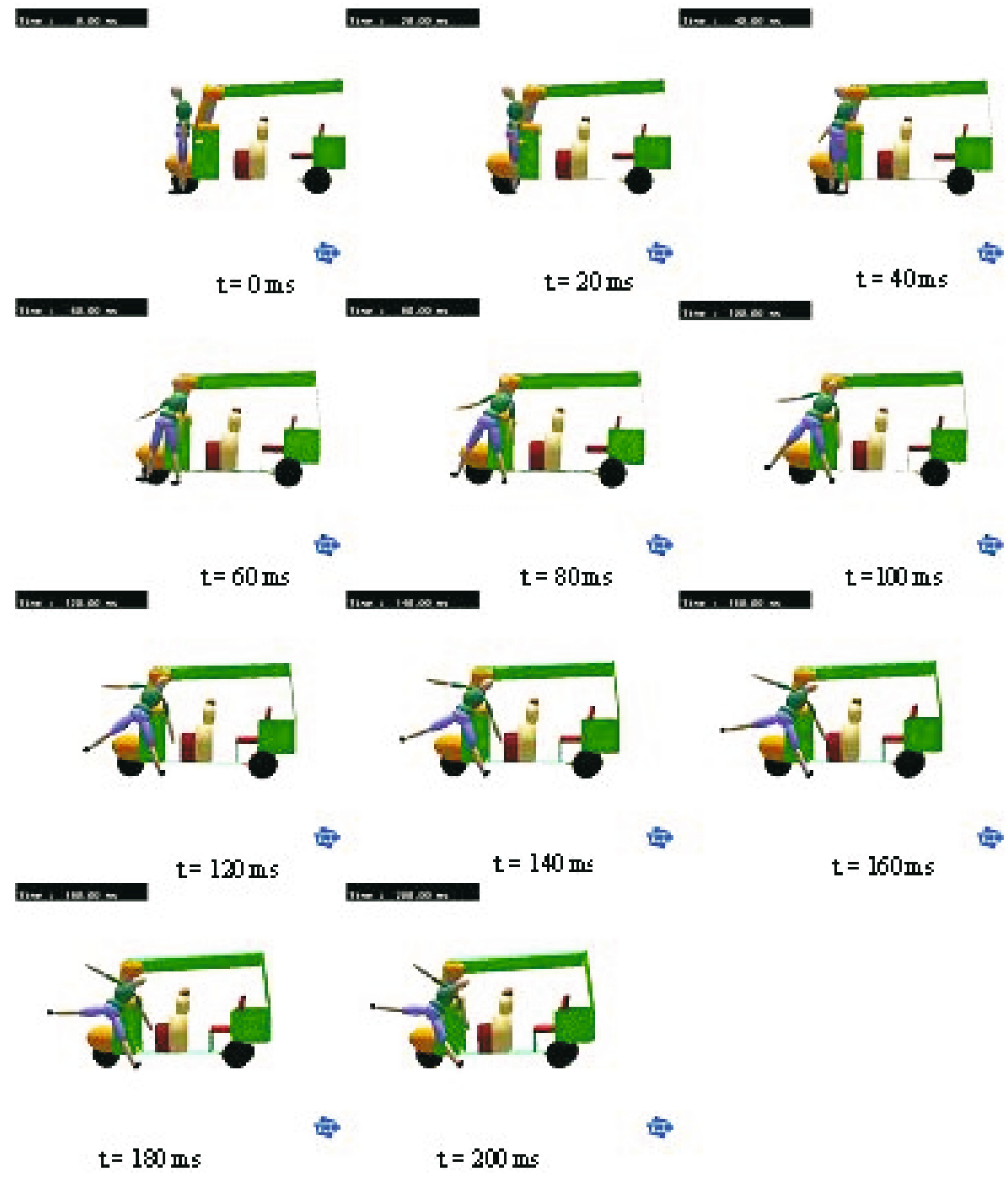

Figure 11. Simulation $\left(\mathrm{MADYMO}^{\mathrm{TM}}\right)$ results showing kinematics of the front offset impact of TWV with pedestrian.

simulations. Analysis indicates that small design changes could significantly enhance safety of occupants and pedestrians.

Figure 11 shows simulation (MADYMO ${ }^{\mathrm{TM}}$ ) results with snapshots of a front offset impact between a pedestrian and TST at $20 \mathrm{~ms}$ intervals. Pedestrian injuries become significant at impact speeds above $30 \mathrm{~km} / \mathrm{h}$ in direct impacts when the pedestrian impacts near the centerline of the vehicle. Head injury criterion (HIC) values are predicted to be between 2400 and 2600 against a tolerable HIC value of 1000 . When the pedestrian is offset the HIC is significantly less as the shield deflects the body sideways. In the central impact case, the lower torso impacts the stiff front surface below the windshield and experiences forces which could cause significant injury. The lower leg experiences higher impact forces in offset impacts as the 

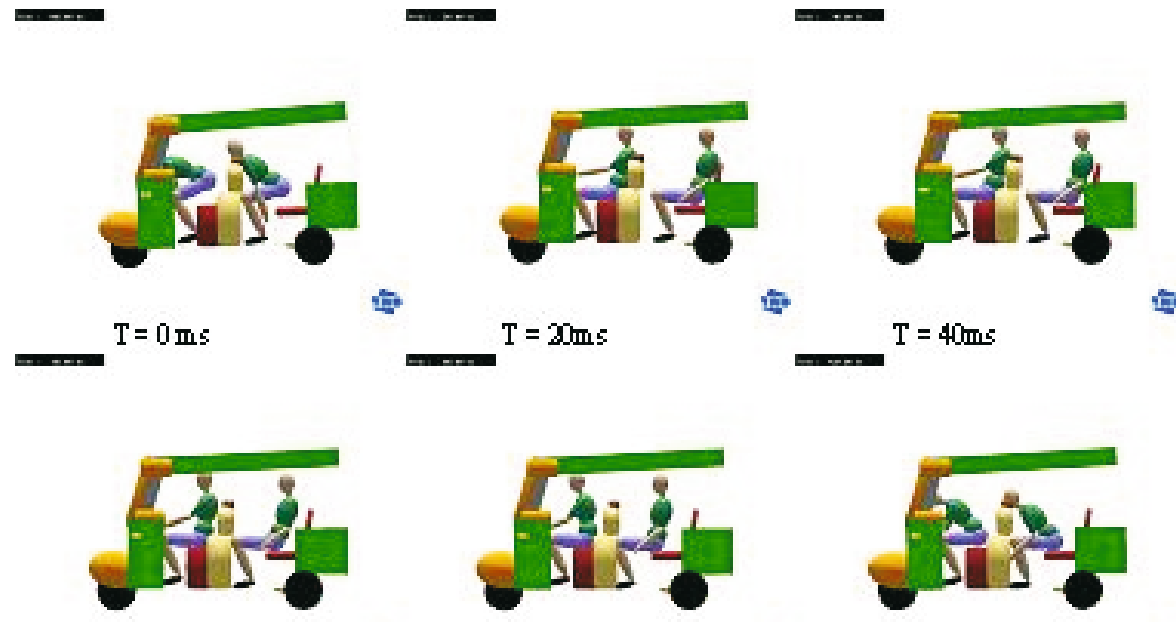

$\mathrm{T}=60 \mathrm{~ms}$

t5

$\mathrm{T}=90 \mathrm{~m} \mathrm{~s}$

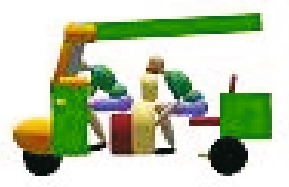

5

$$
\mathrm{T}=100 \mathrm{~ms}
$$

도
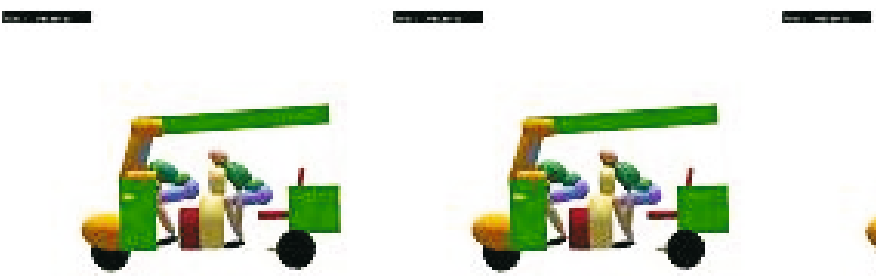

단
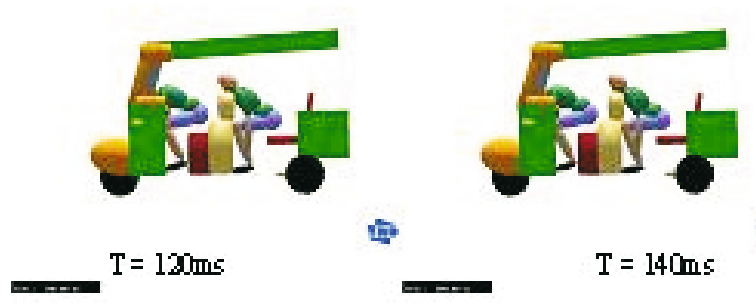

나
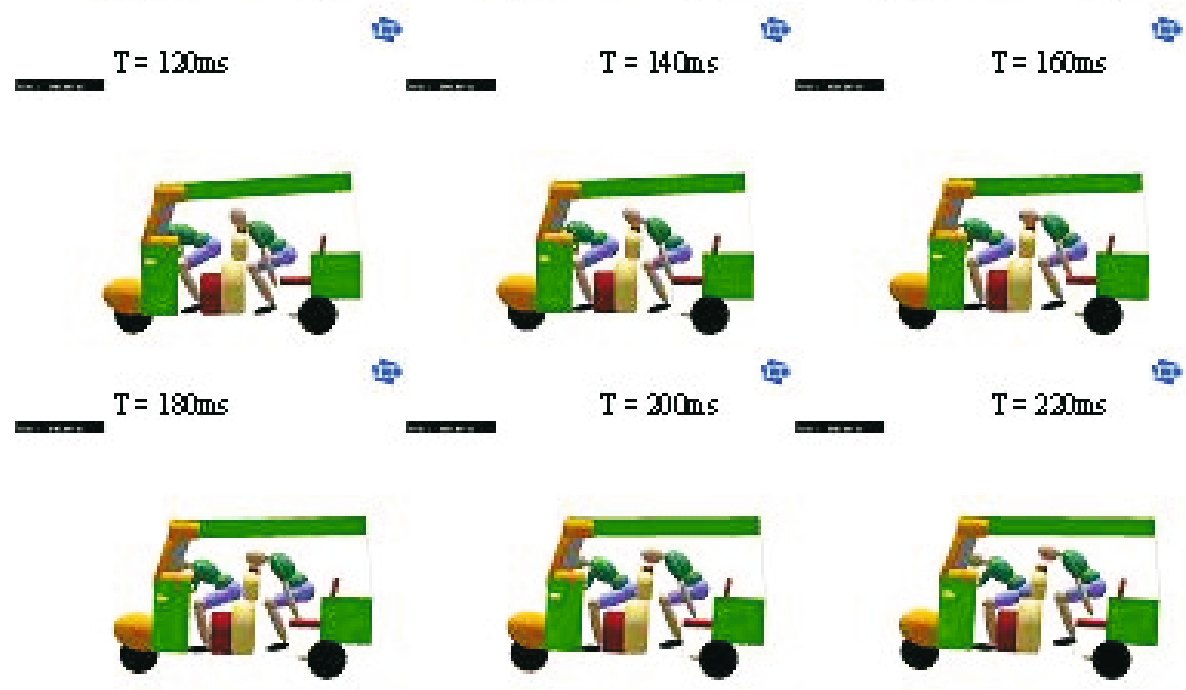

$\mathrm{T}=240 \mathrm{~ms}$

tis $\mathrm{T}=250 \mathrm{~ms}$ $\mathrm{T}=280 \mathrm{~ms}$

安

它

Figure 12. Simulation (MADYMO ${ }^{\mathrm{TM}}$ ) results showing kinematics of impact of TWV with a rigid wall. 
pedestrian twists on impact and could cause lower limb fractures. With changes in stiffness of the areas where the head makes contact by padding the head injury level can be reduced significantly from the critical level and made tolerable at $30 \mathrm{~km} / \mathrm{h}$ impacts. No convenient way was found to reduce lower limb impact forces with the current design.

By crashing a TWV into a rigid barrier, it was determined that the retardation pulse is about $1.5 \mathrm{~s}$ duration. A $1.5 \mathrm{~s}$ sinusoidal pulse was used for simulations. Figure 12 shows snapshots of the simulation at $20 \mathrm{~ms}$ intervals.

In case of frontal rigid barrier impacts at $30 \mathrm{~km} / \mathrm{h}$, both the driver and the passenger have a very high probability of suffering serious head and upper leg (femur) injuries. The knees of passengers and the driver impact rigid surfaces inside the vehicle. It is possible to significantly reduce severity of upper leg injuries by providing padding at the contact points. Head injury severity can be reduced by providing less stiff impact surfaces at the contact point for the passengers and with similar modifications in the driver cabin windshield area. Provision of lap belts does not seem to benefit either the driver or the passenger however, provision of lap and shoulder belts for both the driver and the passenger show major safety benefits. Enabling shoulder belts would require inclusion of load bearing structures for anchoring of the shoulder belts which is not present in current models.

\section{Conclusion}

A systematic analysis of safety issues in TWV has been presented. The rollover propensity of the commonly used TWV using the latest maneuverability assessment tests has been assessed using an in-house mathematical model implemented in MATLAB ${ }^{\mathrm{TM}}$. Measurements to build the models and experiments to validate some of the models were conducted. The optimum configuration of the TWV to minimise rollover propensity was established. It was determined through FE simulations that even if rollover is initiated, the commercial TWV model studied is not predicted to flip over to its side as the vehicle frame acts as an outrigger.

The injury to occupants and pedestrians in the crash incidents was estimated through rigid body simulations implemented in $\mathrm{MADYMO}^{\mathrm{TM}}$. It is predicted that some cost effective safety measures are possible.

\section{References}

Bekker M G 1962 Theory of land locomotion - the mechanics of vehicle mobility (Ann Arbor, The University of Michigan Press)

Dandona R, Mishra A 2004 Deaths due to road traffic crashes in Hyderabad city in India: need for strengthening surveillance. Nat. Med. J. India 17(2): 74-79

Dhakal S 2004 Urban energy use and greenhouse gas emissions in Asian mega cities: Policies for a sustainable future (Kitakyushu, Japan Institute of Global Environmental Strategies)

DeLisle A, Laberge-Nadeau C, Brown B 1988 Characteristics of three- and four-wheeled all-terrain vehicle accidents in Quebec. Accid. Anal. \& Prev. 20:5 357-366

Forkenbrock G J, Garrott W R, Heitz M, O'Harra B C 2002 A comprehensive experimental examination of test maneuvers that may induce on-road, untripped light vehicle rollover - Phase IV of NHTSA's light vehicle rollover research program, NHTSA technical report, DOT HS 809513

Forkenbrock G J, Garrott W R, Boyd P 2003 An overview of NHTSA's recent light vehicle rollover dynamic propensity research and consumer information program. Proceedings of ESV conference (Nagoya, Japan, Paper No. 488) 
Garrott W R, Howe J G, Forkenbrock G 1999 An experimental examination of selected maneuvers that may induce on-road untripped, light vehicle rollover - Phase II of NHTSA's 1997-1998 vehicle rollover research program, DOT HS 808977

Gawade T R, Mukherjee S and Mohan D. 2005 Six-degree-of-freedom three-wheeled-vehicle model validation. Proceedings of the I MECH E Part D J. Automob. Eng. 219(4): 487-498

Gillespie T D 1992 Fundamentals of vehicle dynamics (SAE, Warrendale)

http://transport.delhigovt.nic.in/info/info8.html, transport department of Govt. of NCT of Delhi Statistics about number of vehicles (downloaded on 30 Nov 2002)

http://www.unescap.org/tctd/pubs/files/review2001_part2.pdf, Part two: land transport: urban transport, railways, roads and road transport (downloaded as on 17 Aug 2003)

http://www.worldbank.org/html/fpd/esmap/pdfs/253-02.pdf, Bangladesh: Reducing emissions from 'baby-taxis' in Dhaka, January 2002, Joint UNDP/World Bank Energy Sector Management Assistance Programme (downloaded as on 17 Aug 2003)

IS 1999 ISO 1995 Earth-moving machinery — human physical dimensions of operators and minimum operator space envelope, Second revision (IS 11115, ISO 3411)

MADYMO theory manual, Version 5.4, TNO Automotive, 1999, pp. 243-258

NASA 1978 Anthropometric source book volume I: Anthropometry for designers. NASA Reference Publication 1024 (Washington DC: National Aeronautics and Space Administration)

Ojha A K 2001 Road accidents in Delhi Accident Research Cell Computer Centre (Delhi Traffic Police) Singh D V, Goel V K, Bhattcharya M 1974 Rolling characteristics of small size pneumatic tyre. The Inst. of Mech. Eng. Auto. Div. 188: 701-713

Van Valkenburgh P G, Klein R H, Kanianthra J 1982 Three-wheel passenger vehicle stability and handling. SAE Trans. 820140: 604-627 